\begin{tabular}{|c|l|}
\hline Title & Geographic variation in a predator-induced defense and its genetic basis \\
\hline Author(s) & Kishida, Osamu; Trussell, Geoffrey C.; Nishimura, Kinya \\
\hline Citation & $\begin{array}{l}\text { Ecology, 88(8), 1948-1954 } \\
\text { https://loi.org/10.1890/07-0132.1 }\end{array}$ \\
\hline Issue Date & 2007-08 \\
\hline Doc URL & http://hdl.handle.net/2115/30177 \\
\hline Type & article \\
\hline File Information & ECOL88-8.pdf \\
\hline
\end{tabular}

Instructions for use 


\title{
GEOGRAPHIC VARIATION IN A PREDATOR-INDUCED DEFENSE AND ITS GENETIC BASIS
}

\author{
Osamu Kishida, ${ }^{1,3}$ Geoffrey C. Trussell, ${ }^{2}$ and Kinya Nishimura ${ }^{1}$ \\ ${ }^{1}$ Graduate School of Fisheries Sciences, Hokkaido University, Hakodate 041-8611, Hokkaido, Japan \\ ${ }^{2}$ Marine Science Center, Northeastern University, 430 Nahant Road, Nahant, Massachusetts 01908 USA
}

\begin{abstract}
Predator-induced morphological defenses are a well-known form of phenotypic plasticity, but we continue to have a limited understanding of geographic variation in these responses and its genetic basis. Here we examine genetic variation and geographic differentiation in the inducible defenses of tadpoles (Rana pirica) in response to predatory salamander larvae (Hynobius retardatus). To do so, we crossed male and female frogs from a "mainland" Japanese island having predaceous salamanders and a more isolated island not having predaceous salamanders and raised resulting offspring in the presence and absence of $H$. retardatus. Mainland tadpoles exhibited a higher capacity to express the inducible morphology (a more bulgy body) than those from the predator-free island, and expression of the bulgy morph in mainland-island hybrids produced phenotypes that were intermediate to those produced by pure crosses. In addition, parental sex had no effect on expression of the bulgy morph. Our results support the hypothesis that geographic variation in inducible defenses is linked to the additive effects of autosomal alleles that are shaped by differences in historical exposure to the inducing predator.
\end{abstract}

Key words: arms race; bulgy; coevolution; costs; genetic variation; inducible defense; inducible offense; local adaptation; phenotypic plasticity; predation risk; salamander; tadpole.

\section{INTRODUCTION}

When confronted with predation risk, numerous taxa can exhibit plastic changes in their chemistry, behavior, or morphology that reduces the likelihood of being consumed (reviewed by Tollrian and Harvell 1999). The study of such inducible defenses has substantially improved our understanding phenotypic evolution and the nature of predator-prey interactions (Miner et al. 2005, Fordyce 2006). Theory predicts that natural selection will favor the evolution of inducible defenses when (1) the risk of predation is unpredictable, (2) there are reliable cues signaling predation risk, and (3) the defended phenotype improves fitness in the presence of predators but is costly in their absence (e.g., Lively 1986a, Clark and Harvell 1992, Moran 1992). A rapidly growing body of work continues to produce results that generally agree with current theory (e.g., Lively 1986b, Trussell 2000a, Van Buskirk 2002).

One issue that has received comparatively less attention is the degree to which prey taxa display geographic variation in their capacity to express inducible morphological defenses and whether such variation is correlated with local predation pressure (but see Lively et al. 2000, Trussell 2000b, Trussell and Smith 2000, Relyea 2002b, Trussell and Nicklin 2002, Laurila et al. 2006). This issue is important because the intensity of interactions between predators and their

Manuscript received 25 January 2007; revised 1 March 2007; accepted 8 March 2007. Corresponding Editor: J. Loman.

${ }^{3}$ E-mail: kishida@fish.hokudai.ac.jp prey can vary substantially across broad spatial scales, as is the case when nonnative predators invade novel habitats (e.g., Trussell and Smith 2000, Freeman and Byers 2006). Hence, attention to geographic variation in prey sensitivity to predation risk may improve our understanding of the role inducible defenses play in community dynamics through trait-mediated indirect interactions (Agrawal 2001, Werner and Peacor 2003) and the potential impact of invasive predators on native communities (Grosholz 2002).

Comparative studies using populations from mainland and isolated oceanic islands provide an excellent opportunity to examine local adaptation in the defensive strategies of terrestrial organisms. Compared to the mainland, isolated islands often have an impoverished fauna (MacArthur and Wilson 1967) and island predator assemblages are thus less diverse than those on the mainland. In addition, geographic separation of mainland and island populations may restrict gene flow between the two, thus enhancing the likelihood of local adaptation (Riechert 1993, Storfer and Sih 1998). For example, previous work examining plant chemical defenses against herbivores on mainland versus more isolated ocean islands (Bryant et al. 1989, Bowen and Van 1997, Vourc'h et al. 2001) found that plants on herbivore-free islands have weaker chemical defenses than those on the mainland where herbivores are abundant.

Amphibian larvae are model organisms for the study of inducible defenses (Van Buskirk and Relyea 1998, Van Buskirk 2002, Relyea 2005, Kishida and Nishimura 
2006). Previous studies have shown that larvae with predator-induced morphologies (such as a higher tail) exhibit increased survivorship when confronted by aquatic insect predators such as dragonfly larvae (Van Buskirk and Relyea 1998, Kishida and Nishimura 2005, Benard 2006). Among anuran species, Rana pirica tadpoles exhibit a unique predator-induced morphological defense (bulgy body) in response to predatory larval salamanders (Hynobius retardatus) in addition to the more common higher tail induced by aquatic insect predator cues (Kishida and Nishimura 2005). The bulgy body prevents gape-limited predators like larval salamanders from swallowing tadpoles but it is ineffective against predatory dragonfly larvae that bite (Kishida and Nishimura 2005). Furthermore, the degree of inducible defense exhibited by $R$. pirica tadpoles appears to coincide with the intensity of predation risk. When $R$. pirica tadpoles are exposed to the predaceous phenotype of $H$. retardatus, which is characterized by a broad head and large mouth, they produce a much more bulgy body than tadpoles exposed to the non-predaceous $H$. retardatus phenotype (Kishida et al. 2006). These results support the hypothesis that the form and degree of inducible defense has evolved to match the predatory tactics of $H$. retardatus larvae.

In Japan, $R$. pirica tadpoles are found on Hokkaido Island (78581.51 $\mathrm{km}^{2}$ in area), which is the main northern island in the Japanese archipelago, as well as on neighboring isolated islands such as Okushiri Island (142.97 $\mathrm{km}^{2}$ and separated from Mainland Hokkaido Island by $61 \mathrm{~km}$ ). Although $H$. retardatus are common on Hokkaido Island, they are absent from Okushiri Island (Takenaka 2000). Okushiri Island has been isolated from Hokkaido for several tens of thousands of years since the end of the last ice age. Hence, the current distribution of both amphibians suggests that mainland and island $R$. pirica populations have experienced different predator histories at least over some time period that may have led to geographic differences in the evolution of their capacity to express inducible defenses.

Given these historical differences in contact history within mainland and island populations of $R$. pirica and $H$. retardatus, we hypothesized that the ability to express bulginess has either decreased or is absent in the island population. Thus, we expected that tadpoles from the Hokkaido population would exhibit a greater capacity to express the bulgy morph in response to H. retardatus than those from Okushiri Island. In addition, by performing a common garden experiment using offspring produced by pure mainland and island crosses as well as by hybrid crosses, we examined both allelic and parental sex effects on expression of the bulgy morph. Our results suggest that geographic differentiation in inducible defenses is correlated with historical differences in predation pressure and that the additive effects of autosomal alleles control the expression of these defenses.

\section{Materials ANd Methods}

On mainland Hokkaido, H. retardatus salamanders and $R$. pirica frogs spawn in variety of ponds such as small ephemeral pools created by melting snow and large permanent ponds (see Plate 1). After hatching, interactions between the larvae of both amphibians are highly intimate in small ponds. Hence, we frequently observe bulgy tadpoles induced by larval $H$. retardatus in Hokkaido ponds from mid spring to early summer. Although the fauna of Okushiri Island includes several reptilian and amphibian species that are native to the mainland, H. retardatus are absent (Takenaka 2000). Okushiri Island has other potential predators of $R$. pirica tadpoles such as larval dragonflies (Sympetum sp.), back swimmers (Notonecta triguttata) and diving beetles (Rhantus pulverosus) that are also found on the mainland. Thus, except for differences in the presence of $H$. retardatus, both populations of $R$. pirica experience similar predator regimes.

To explore whether geographic variation in the expression of the bulgy morphology in response to $H$. retardatus has a genetic basis, we performed artificial fertilizations with adult male and female $R$. pirica collected from Hokkaido and Okushiri populations (i.e., the four full-sib genetic populations; female origin $\times$ male origin; Hokkaido $\times$ Hokkaido $[\mathrm{HH}]$, Hokkaido $\times$ Okushiri [HO], Okushiri $\times$ Hokkaido $[\mathrm{OH}]$, and Okushiri $\times$ Okushiri $[\mathrm{OO}]$ ), and assigned the tadpoles of each genetic population (i.e., cross) to either a predator environment (exposure to larval $H$. retardatus) or a nopredator environment.

Adult frogs of $R$. pirica were collected from several breeding ponds on Okushiri Island and on the Oshima peninsula of Hokkaido Island in early April 2005 (at onset of spawning). Artificial fertilization was conducted by randomly choosing five males and five females from each population. A breeding pair of one male and female was crossed in a blocked design (i.e., crossings between two sexes with two populations were conducted in five blocks; Appendix A). The body lengths of frogs used were: Hokkaido male, $53.67 \pm 3.17 \mathrm{~mm}$; Okushiri male, $52.63 \pm 3.69 \mathrm{~mm}$; Hokkaido female, $60.59 \pm 4.82$ $\mathrm{mm}$, and Okushiri female, $62.56 \pm 5.08 \mathrm{~mm}$ (mean \pm $\mathrm{SD}, n=5$ ). Artificial fertilizations were performed on 17 April 2005 following the methods of Laugen et al. (2002). The fertilized eggs of the four full-sib genetic populations were kept separately in 2-L aquaria at a water temperature of $16^{\circ} \mathrm{C}$. This approach was highly successful (more than 95\% of all eggs used were fertilized and all fertilized eggs developed) and resulting tadpoles hatched between 21 and 22 April 2005. Full-sib hatchlings were kept in the holding tanks filled with 2 L of aged tap water (changed every two days) and fed fish food ad libitum.

Hynobius retardatus larvae were obtained from several egg masses collected from a pond in Sekinai, Hokkaido on 30 March 2005. Hynobius retardatus hatchlings were 
reared in $13-\mathrm{L}$ tanks with water $\left(10^{\circ} \mathrm{C}\right.$ and changed every two days) and fed small $R$. pirica tadpoles ad libitum.

On 30 April 2005 we began the induction experiment by exposing individuals from each of the four crosses (Appendix A) to the presence or absence of $H$. retardatus. The experimental units were $4.5-\mathrm{L}$ aquaria $(28.5 \times 16.5 \times 9.5 \mathrm{~cm})$ arranged in five experimental blocks. Sixty similarly sized tadpoles of each full-sibling cross were randomly chosen and assigned to either predator aquaria having one $H$. retardatus larva or to control aquaria with no predator. Thus there were altogether 40 aquaria and 2400 tadpoles involved. Mean snout-vent lengths of tadpoles at the beginning of the experiment were: $\mathrm{HH}=7.23 \pm 0.51 \mathrm{~mm}, \mathrm{HO}=7.49 \pm$ $0.62 \mathrm{~mm}, \mathrm{OH}=7.15 \pm 0.39 \mathrm{~mm}$, and $\mathrm{OO}=7.18 \pm 0.61$ $\mathrm{mm}$ (mean $\pm \mathrm{SD}, n=15)$. Tadpoles were fed daily with an ad libitum amount of rabbit chow and rearing water was changed every two days throughout the experiment. $H$. retardatus larvae used in the predator treatment were randomly chosen from similarly sized individuals (snout-vent length $=16.45 \pm 0.76 \mathrm{~mm}$, mean $\pm \mathrm{SD}, n$ $=20$ ) housed in several holding tanks.

To minimize predation on tadpoles, salamander larvae were replaced daily with individuals maintained in holding tanks having an ad libitum supply of $R$. pirica tadpoles. Replacement salamander larvae were randomly chosen from holding tanks. However, despite this approach actual predation, while low (the number of tadpoles consumed in the predator treatment was less than two per day), still occurred in the predator treatment. Hence, to maintain similar tadpole densities across all aquaria, we manually removed randomly selected tadpoles from appropriate aquaria so that the rate of tadpole loss was five individuals every two days (i.e., 60 individuals at the start of the experiment, 55 after two days, 50 after four days, and so on).

After 10 days, we ended the experiment and randomly selected 16 tadpoles from each predator treatment aquarium and 8 tadpoles from each control aquarium that were killed in $10 \%$ ethanol. Photographs in lateral views were taken in a small glass chamber and resulting images were projected onto a computer monitor and two traits were digitized; body length (from the tip of the snout to the tail joint) and maximum body depth. The body depth is an appropriate indicator of bulginess (Kishida and Nishimura 2004). We adopted body length as the canonical size measurement because it is stable, whereas most other measurable traits (e.g., body width, tail length, and total length) are changed by the induction of the bulgy phenotype (i.e., neither a composite variable of various morphological traits such as the first principal component in a principal components analysis nor mass is an appropriate canonical size measurement). Because of the positive covariance between body depth and body length, the body depth of each individual was adjusted relative to that at a body-length mean of $10.32 \mathrm{~mm}$, which was obtained from regressions of body depth $(y)$ as a function of body length $(x)$ for individuals in each treatment in the experiment.

Although we tried to prevent predation by having satiated salamanders in the predator treatment, predation events still occurred. During the experiment, the number of tadpoles consumed from the $\mathrm{HH}, \mathrm{HO}, \mathrm{OH}$, and $\mathrm{OO}$ populations were $11.8 \pm 2.59,10.4 \pm 2.30,11.2$ \pm 1.64 , and $12.4 \pm 1.82$ (mean $\pm \mathrm{SD}, n=5$ ), respectively. To exclude the possibility that selective predation on individuals having reduced levels of inducible defense was responsible for observed morphological differences in the predator vs. control treatments, we performed a correction before statistical analyses (see Appendix B). For this correction, we deleted some individuals having more bulgy bodies from the sample in each aquarium in the predator treatments. After correction, mean trait values for each aquarium that were used in statistical analyses.

\section{RESUlTS}

The three-way ANOVA including the effects of female origin, male origin, and predator treatment as main effects and their interaction effects was conducted on the mean trait values. Male $\left(F_{1,28}=27.05, P<\right.$ $0.0001)$ and female origin $\left(F_{1,28}=18.85, P<0.0001\right)$ and predator presence $\left(F_{1,28}=583.02, P<0.0001\right)$ all had significant effects on expression of the bulgy morph. Importantly, the male origin $\times$ predator treatment $\left(F_{1,28}\right.$ $=14.65, P=0.001)$ and female origin $\times$ predator treatment $\left(F_{1,28}=16.69, P<0.0001\right)$ interactions were significant but the male origin $\times$ female origin $\left(F_{1,28}=\right.$ 1.802, $P=0.19)$ and the male origin $\times$ female origin $\times$ predation treatment $\left(F_{1,28}=0.15, P=0.70\right)$ interactions were not significant (for full analysis, see Appendix C: Table C1). For all four crosses, Tukey post hoc tests revealed no differences in the body depth of tadpoles subject to the no-predator treatment and these nopredator phenotypes from each cross were significantly different from those in the predator treatment (Fig. 1). These results indicate that tadpoles developed similar, non-bulgy phenotypes in the absence of predation risk and that tadpoles regardless of their origin are capable of expressing some bulginess in response to predation risk (Figs. 1 and 2).

Given that tadpoles had similar body depths in the no-predator treatment regardless of their origin, the capacity to express bulginess can be evaluated by comparing the values of relative body depth in the predator treatment. In the predator treatment, the Hokkaido population $(\mathrm{HH})$ had the greatest body depth, the Okushiri population (OO) had the lowest body depth, and their hybrids ( $\mathrm{HO}$ and $\mathrm{OH}$ ) produced phenotypes having intermediate body depths (Fig. 1). These results clearly indicate that Hokkaido tadpoles have a greater capacity to express inducible defenses in response to $H$. retardatus predation risk than Okushiri tadpoles, and strongly suggest that the observed 


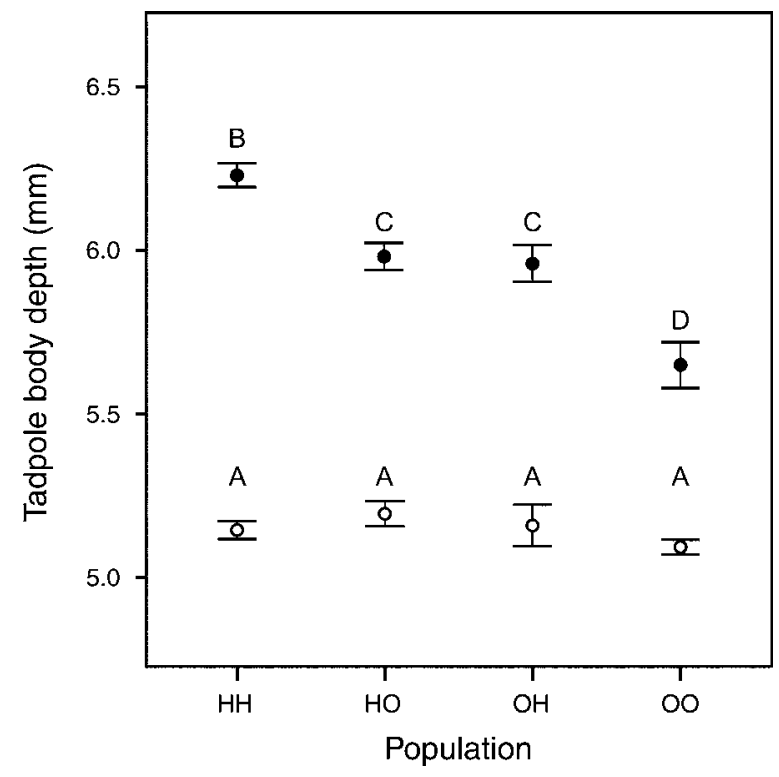

FIG. 1. Size-adjusted body depth of Rana pirica tadpoles of four genetic populations subjected to the predator treatment (solid circles) or control treatment (open circles): $\mathrm{HH}$ is Hokkaido $\times$ Hokkaido original population; $\mathrm{HO}$ and $\mathrm{OH}$ are Hokkaido $\times$ Okushiri hybrid populations; OO is Okushiri original population. Error bars denote one standard error $(n=$ 5). Means not sharing the same letter are significantly different (Tukey's test).

population-specific differences in expression of the bulgy morph have a genetic basis.

To examine the nature of allelic effects on expression of the bulgy morph, we conducted a two-way ANOVA on tadpole body depth data solely from the predator treatment with the male origin and female origin as main effects. The effects of male $\left(F_{1,12}=45.14, P<0.0001\right)$ and female $\left(F_{1,12}=39.33, P<0.0001\right)$ origin were again significant but there was no significant interaction between male and female origin $\left(F_{1,12}=0.36, P=0.56\right.$; for full analysis, see Appendix C: Table C2). This result and the equivalent expression of the bulgy morph in both hybrids ( $\mathrm{HO}$ and $\mathrm{OH}$; Fig. 1) suggest that allelic effects on expression of the bulgy morph are strictly additive.

\section{Discussion}

We found that the longer contact history with predatory salamanders on the mainland has favored $R$. pirica tadpoles having a greater capacity to express the bulgy phenotype whereas the capacity to do so is lower on the predator-free island. Thus, it appears that increased predation pressure by $H$. retardatus has favored the evolution of increased plasticity in the mainland population. The bulgy morph is adaptive in reducing predation risk in mainland $R$. pirica populations because the ability of larval $H$. retardatus to consume tadpoles is dictated by their gape size (Kishida and Nishimura 2004). In contrast, other important predator species, (e.g., larval dragonflies such as Aeshna nifroflava) do not induce the bulgy phenotype because it does not reduce the efficacy of their tactics (Kishida and Nishimura 2005).

Previous work in this system suggests that phenotypic plasticity has played an important role in the coevolutionary dynamics between $R$. pirica tadpoles and predatory salamanders. For example, high tadpole densities induce production of the predaceous morph of $H$. retardatus, which is more successful at consuming tadpoles (Michimae and Wakahara 2002). Moreover, $H$. retardatus inhabiting ponds with high densities of $R$. pirica tadpoles exhibit a greater capacity to express the predaceous morph than those inhabiting ponds with low tadpole densities (Michimae 2006). Finally, the extent of bulginess induction in $R$. pirica tadpoles is highly correlated with the degree of phenotype-dependent predation risk imposed by larval $H$. retardatus; tadpoles

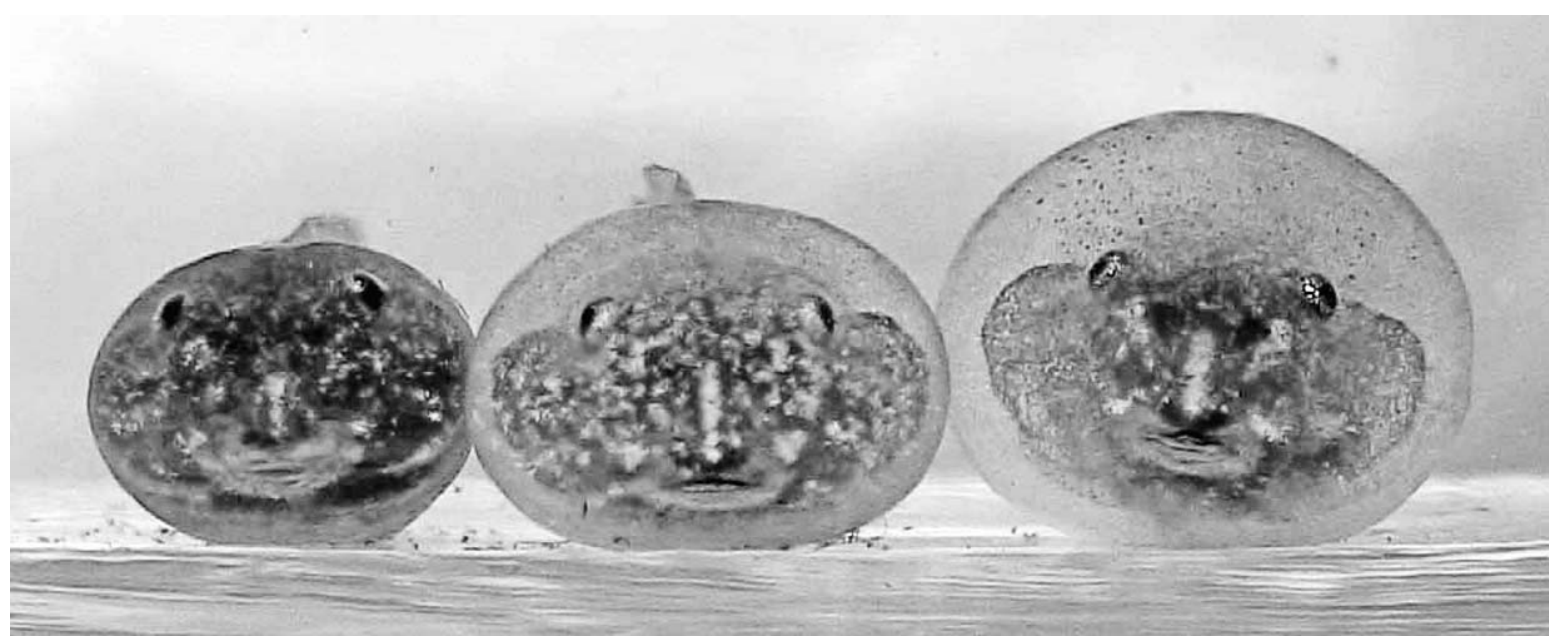

FIG. 2. Photo image of Rana pirica tadpoles: non-induced basic tadpoles of Hokkaido populations (left); bulgy tadpoles of Okushiri population (center); bulgy tadpoles of Hokkaido population (right). 


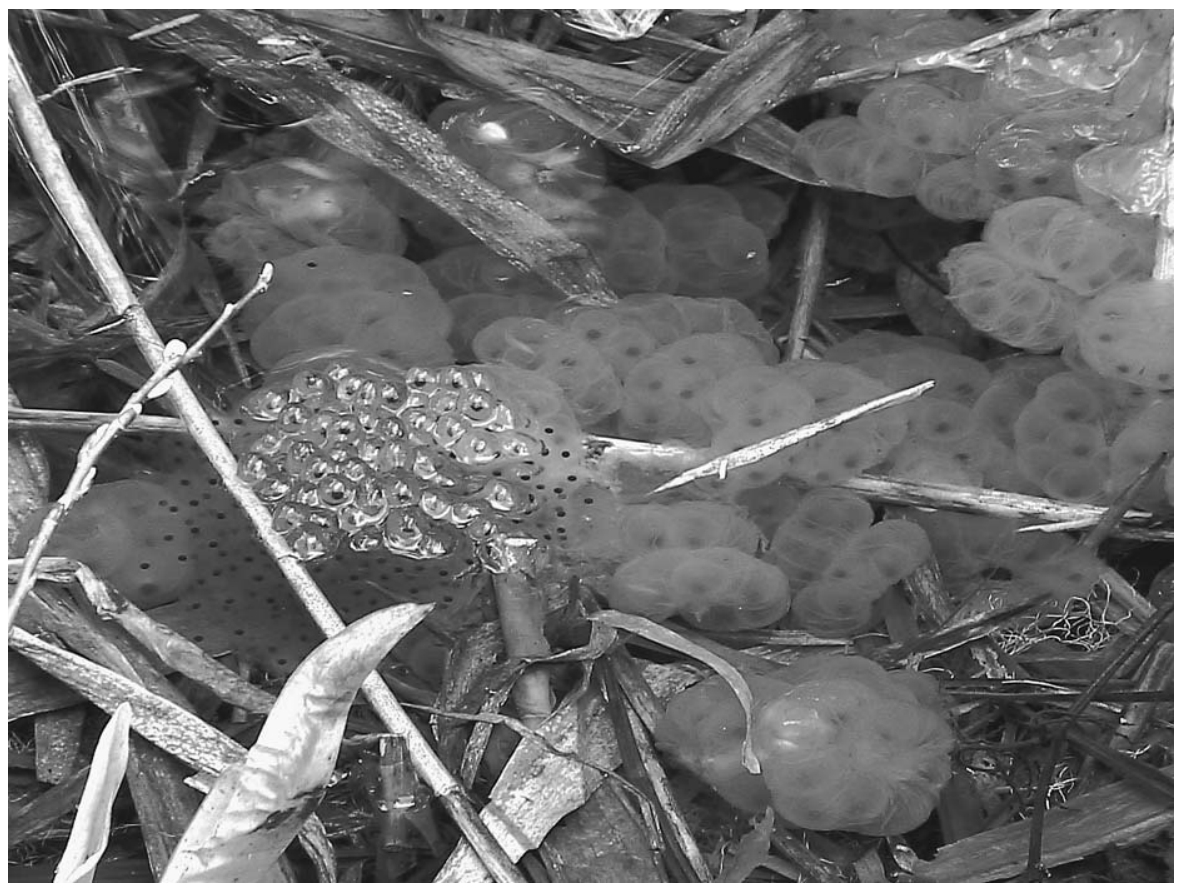

Plate 1. Spawned egg sacs of Hynobius retardatus salamanders and an egg mass of the frog Rana pirica in a small pond on Hokkaido Island, Japan. After hatching, both amphibian larvae form intimate predator-prey relationships. Photo credit: O. Kishida.

exposed to the predaceous $H$. retardatus phenotype exhibit bulgier phenotypes than those exposed to the non-predaceous $H$. retardatus phenotype (Kishida et al. 2006). The reciprocal plasticity evident in this two species may reflect a finely tuned coevolutionary arms race.

Biogeographic records documenting the absence of $H$. retardatus on Okushiri Island suggest that $R$. pirica tadpoles have escaped predation pressure by $H$. retardatus at least for some time period on the island. Interestingly, tadpoles from Okushiri Island have the capacity to express the bulgy morph but their response is considerably smaller than that displayed by the Hokkaido population (Figs. 1 and 2). The ability to express this inducible defense may be an ancestral character state that has been retained in the Okushiri population but the magnitude of expression has decreased in response to reduced predation risk on the island. The reduced plasticity exhibited by the Okushiri population may be favored by selection to minimize unnecessary costs of plasticity (but see DeWitt 1998, Relyea 2002a) and/or mutational degradation of the inducibility with random genetic drift in the absence of the predator (for details on degradation, see Masel et al. 2007).

There have been relatively few studies on induced morphological defenses in response to geographic variation in predation pressure (but see Barry and Bayly 1985, Spitze 1992, Trussell 2000b, Trussell and Smith 2000, Trussell and Nicklin 2002) and this is especially true for larval amphibians (but see Lardner 1998, Relyea 2002b, Laurila et al. 2006). Recent work by Laurila et al. (2006) on geographic differences in predation pressure and induced morphological defenses (e.g., increased tail depth) in Swedish tadpoles (Rana arvalis) produced results generally consistent with our study. $R$. arvalis tadpoles from a mainland and an island population exhibited similar degrees of inducible morphological defense in response to predator species found in both areas (dragonfly larvae and newts). However, tadpoles from each population responded very differently to risk cues from predatory sticklebacks that are found only on the island. Laurila et al. (2006) suggest that the different responses of the island tadpoles may reflect local adaptation to stickleback predation pressure. However, this hypothesis requires more attention because observed differences in morphological plasticity did not lead to improved survivorship of island vs. mainland tadpoles when exposed to free-ranging sticklebacks.

Our work and that of Laurila et al. (2006) suggests that geographic variation in the presence and absence of a particular predator can lead to different magnitudes or types of inducible defense. Nevertheless, more work is needed to better understand how predation pressure shapes geographic variation in the evolution of inducible defenses. Theory suggests that fixed rather than inducible defenses should be favored by natural selection as predation pressure becomes more predictable (Tollrian and Harvell 1999). Studies on zooplankton (Barry and Bayly 1985) and marine snails (Trussell 2000b, Trussell and Smith 2000) showing either the absence of, or a 
reduction in, inducible defense expression with more consistent predator presence agrees with this prediction. In contrast, our study found that plasticity was greater in the Hokkaido population that has had a longer contact history with predatory salamanders. Hence, attention to within habitat (i.e., within mainland) variability in predation risk (see Relyea 2002b) rather than absolute historical differences in predation risk also may be important to the plasticity patterns we observed.

The genetic basis of phenotypic plasticity continues to be a focal issue for evolutionary ecologists because this knowledge is crucial to understanding its evolution (Scheiner and Lyman 1989, Pigliucci 2005). To our knowledge, only one study (Relyea 2005) has explicitly examined the genetic basis of inducible defenses in anuran tadpoles. Using a half-sib design, Relyea (2005) found relatively high heritability of inducible defenses and genetic correlations among inducible traits (behavior, morphology, and life history) in wood frog (Rana sylvatica) tadpoles. These results indicate that both trait means and plasticity can be acted upon by natural selection. Our full-sib experiment also identified a strong genetic basis to the inducible bulgy morph and revealed substantial genetic differentiation among the mainland and island population in the capacity to express bulginess. Pure mainland crosses $(\mathrm{HH})$ displayed the greatest amount of expression of the bulgy morph whereas pure island crosses (OO) displayed significantly less. The expression values of bulginess in hybrid crosses was the same regardless of parental origin and how they were crossed (male vs. female) indicating no maternal or paternal control on expression of the bulgy morph. This lack of parental dependence implies that expression of the bulgy morph is controlled by autosomal alleles. It is also important to note that the hybrid crosses produced bulgy phenotypes having values intermediate to those of both pure crosses suggesting that allelic effects are additive.

The production of inducible defenses is the result of a complicated physiological and developmental pathway from signal reception to the production of the actual phenotype and it is likely that numerous functional genes govern these responses (Gilbert 2001, Windig et al. 2004). Although this study has shed light on the general genetic architecture of expression of the bulgy morph, molecular approaches are beginning to more precisely describe the linkage between genetics and inducible phenotypic expression (Mori et al. 2005). Using cDNA subtraction and microarray analysis, Mori et al. (2005) identified differences between typical and bulgy tadpoles in the transcription of a set of genes in the body epithelial tissue. In bulgy tadpoles, genes involved with fibrinolysis were down-regulated and those involved with the crucial role of intracellular assembly were upregulated. We suggest that the geographic differences in expression of the bulgy morph documented here may reflect differences in these, and perhaps other, candidate functional genes. Further exploration of these and other candidates' genes and the importance of inducible defenses to predator-prey interactions in this system may allow us to identify a link between molecular genetics and ecological dynamics.

\section{ACKNOWLEDGMENTS}

We are very grateful to Tadashi Iwami and Gen Miyazaki for assisting with the experimental work and for constructive comments on the manuscript. We also thank Tsutou Hirose, Takuya Ikawa, Mamoru Kawamoto, Hirofumi Michimae, Kaita Nozaki, Nariko Oka, Nao Sugawara, Sen Takenaka, Yoichiro Tamori, Masami Wakahara, and Masanori Yokoyama for their advice and support. This work was supported by a Grant-in-Aid for Scientific Research (no. 16370008) to K. Nishimura from the Ministry of Education, Culture, Sports, Science, and Technology, and in part by a Grant-in-Aid for Research Young Scientists (no. 09035) to O. Kishida.

\section{Literature Cited}

Agrawal, A. A. 2001. Phenotypic plasticity in the interactions and evolution of species. Science 294:321-326.

Barry, M. J., and I. A. E. Bayly. 1985. Further studies on predator induction of crests in Australian Daphnia and the effects of crests on predation. Australian Journal of Marine and Freshwater Research 36:519-535.

Benard, M. F. 2006. Survival trade-offs between two predatorinduced phenotypes in Pacific treefrogs (Pseudacris regilla). Ecology 87:340-346.

Bowen, L., and V. D. Van. 1997. Insular endemic plants lack defenses against herbivores. Conservation Biology 11:12491254.

Bryant, J., J. Tahvanainen, M. Sulkinoja, R. Julkunen-Tiitto, P. Reichardt, and T. Green. 1989. Biogeographic evidence for the evolution of chemical defense by boreal birch and willow against mammalian browsing. American Naturalist 134:20 34.

Clark, C. W., and C. D. Harvell. 1992. Inducible defenses and the allocation of resources: a minimal model. American Naturalist 139:521-539.

DeWitt, T. J. 1998. Costs and limits of phenotypic plasticity: Tests with predator-induced morphology and life history in a freshwater snail. Journal of Evolutionary Biology 11:465480.

Fordyce, J. A. 2006. The evolutionary consequences of ecological interactions mediated through phenotypic plasticity. Journal of Experimental Biology 209:2377-2383.

Freeman, A. S., and J. E. Byers. 2006. Divergent induced responses to an invasive predator in marine mussel populations. Science 313:831-833.

Gilbert, S. F. 2001. Ecological developmental biology: developmental biology meets the real world. Developmental Biology 233:1-12.

Grosholz, E. D. 2002. Ecological and evolutionary consequences of coastal invasions. Trends in Ecology and Evolution 17: 22-27.

Kishida, O., Y. Mizuta, and K. Nishimura. 2006. Reciprocal phenotypic plasticity in a predator-prey interaction between larval amphibians. Ecology 87:1599-1604.

Kishida, O., and K. Nishimura. 2004. Bulgy tadpoles: inducible defense morph. Oecologia 140:414-421.

Kishida, O., and K. Nishimura. 2005. Multiple inducible defences against multiple predators in the anuran tadpole, Rana pirica. Evolutionary Ecology Research 7:619-631.

Kishida, O., and K. Nishimura. 2006. Flexible architecture of inducible morphological plasticity. Journal of Animal Ecology 75:705-712.

Lardner, B. 1998. Plasticity or fixed adaptive traits? Strategies for predation avoidance in Rana arvalis tadpoles. Oecologia 117:119-126. 
Laugen, A. T., A. Laurila, and J. Merila. 2002. Maternal and genetic contributions to geographical variation in Rana temporaria larval life-history traits. Biological Journal of the Linnean Society 76:61-70.

Laurila, A., S. Pakkasmaa, and J. Merila. 2006. Population divergence in growth rate and antipredator defences in Rana arvalis. Oecologia 147:585-595.

Lively, C. M. 1986a. Canalization versus developmental conversion in a spatially variable environment. American Naturalist 128:561-572.

Lively, C. M. 1986b. Predator-induced shell dimorphism in the acorn barnacle Chthamalus anisopoma. Evolution 40:232242.

Lively, C. M., W. N. Hazel, M. J. Schellenberger, and K. S. Michelson. 2000. Predator-induced defense: variation for inducibility in an intertidal barnacle. Ecology 81:1240-1247.

MacArthur, R. H., and E. O. Wilson. 1967. The theory of island biogeography. Princeton University Press, Princeton, New Jersey, USA.

Masel, J., O. D. King, and H. Maughan. 2007. The loss of adaptive plasticity during long periods of environmental stasis. American Naturalist 169:38-46.

Michimae, H. 2006. Differentiated phenotypic plasticity in larvae of the cannibalistic salamander Hynobius retardatus. Behavioural Ecology and Sociobiology 60:205-211.

Michimae, H., and M. Wakahara. 2002. A tadpole-induced polyphenism in the salamander Hynobius retardatus. Evolution 56:2029-2038.

Miner, B. G., S. E. Sultan, S. G. Morgan, D. K. Padilla, and R. A. Relyea. 2005. Ecological consequences of phenotypic plasticity. Trends in Ecology and Evolution 20:685-692.

Moran, N. 1992. The evolutionary maintenance of alternative phenotypes. American Naturalist 139:971-989.

Mori, T., I. Hiraka, Y. Kurata, H. Kawachi, O. Kishida, and K. Nishimura. 2005. Genetic basis of phenotypic plasticity for predator-induced morphological defenses in anuran tadpole, Rana pirica, using cDNA subtraction and microarray analysis. Biochemical Biophysical Research Communications 330:1138-1145.

Pigliucci, M. 2005. Evolution of phenotypic plasticity: where are we going now? Trends in Ecology and Evolution 20:481486.

Relyea, R. A. 2002a. Costs of phenotypic plasticity. American Naturalist 159:272-282.

Relyea, R. A. 2002b. Local population differences in phenotypic plasticity: predator-induced changes in wood frog tadpoles. Ecological Monographs 72:77-93.

Relyea, R. A. 2005. The heritability of inducible defenses in tadpoles. Journal of Evolutionary Biology 18:856-866.
Riechert, S. E. 1993. Investigation of potential gene flow limitation of behavioral adaptation in an arid lands spider. Behavioural Ecology and Sociobiology 32:355-363.

Scheiner, S. M., and R. F. Lyman. 1989. The genetics of phenotypic plasticity. I. Heritability. Journal of Evolutionary Biology 2:95-107.

Spitze, K. 1992. Predator-mediated plasticity of prey lifehistory and morphology: Chaoborus americanus predation on Daphnia pulex. American Naturalist 139:229-247.

Storfer, A., and A. Sih. 1998. Gene flow and ineffective antipredator behavior in a stream-breeding salamander. Evolution 52:558-565.

Takenaka, S. 2000. Amphibians and reptiles in Okushiri Island. Bulletin of the Herpetological Society of Japan 2000:66. [In Japanese.]

Tollrian, R., and C. D. Harvell. 1999. The ecology and evolution of inducible defenses. Princeton University Press, Princeton, New Jersey, USA.

Trussell, G. C. 2000a. Phenotypic clines, plasticity, and morphological trade-offs in an intertidal snail. Evolution 54:151-166.

Trussell, G. C. 2000b. Predator-induced plasticity and morphological trade-offs in latitudinally separated populations of Littorina obtusata. Evolutionary Ecology Research 2:803822.

Trussell, G. C., and M. O. Nicklin. 2002. Cue sensitivity, inducible defense, and trade-offs in a marine snail. Ecology $83: 1635-1647$.

Trussell, G. C., and L. D. Smith. 2000. Induced defenses in response to an invading crab predator: An explanation of historical and geographic phenotypic change. Proceedings of the National Academy of Sciences (USA) 97:2123-2127.

Van Buskirk, J. 2002. A comparative test of the adaptive plasticity hypothesis: relationship between habitat and phenotype in anuran larvae. American Naturalist 160:87102.

Van Buskirk, J., and R. A. Relyea. 1998. Selection for phenotypic plasticity in Rana sylvatica tadpoles. Biological Journal of the Linnean Society 65:301-328.

Vourc'h, G., J. L. Martin, P. Duncan, J. Escarre, and T. P. Clausen. 2001. Defensive adaptations of Thuja plicata to ungulate browsing: a comparative study between mainland and island populations. Oecologia 126:84-93.

Werner, E. E., and S. D. Peacor. 2003. A review of traitmediated indirect interactions in ecological communities. Ecology 84:1083-1100.

Windig, J. J., C. G. F. de Kovel, and G. de Jong. 2004. Genetics and mechanics of plasticity. Pages 31-49 in T. J. Dewitt and S. M. Scheiner, editors. Phenotypic plasticity. Oxford University Press, New York, New York, USA.

\section{APPENDIX A}

Experimental design (Ecological Archives E088-116-A1).

\section{APPENDIX B}

Data correction method used to exclude effect of possible selective predation on the less induced tadpoles (Ecological Archives E088-116-A2).

\section{APPENDIX C}

Tables showing ANOVA designs (Ecological Archives E088-116-A3). 